P20 (continued)

an intervention that aims at improving FV intake in college students.

Funding: University of Dayton Research Institute

\section{P21 Cost Increase to Follow USDA MyPlate Diet in College-Aged Students}

Rashel L. Clark, BS, RDN, West Virginia University; Oluremi A. Famodu, MS, RDN; Alex Morrill;

Caitlin Warner, BS; Jane Ruseski, PhD;

Pamela J. Murray, MD; Sarah Colby, PhD, RDN, University of Tennessee; Melissa D. Olfert, DPH, DrPH, RDN, melissa. olfert@mail.wvu.edu, West Virginia University, 333 AG SC Building G28, Morgantown, WV 26506

Objective: The perceived high cost of healthier food items is a common barrier for individuals seeking to improve personal dietary patterns. FRUVEDomics Pilot Study examined food costs of college students enrolled in a non-diet free-living intervention. The 8-week dietary intervention focused on half the plate being fruits and vegetables, based on the USDA MyPlate.

Method: Meal receipts were obtained weekly from participants $(n=48)$ enrolled in the 8-week dietary intervention. Three participants were excluded from the analysis, based on exclusion criteria of medication use and campus dining meal plan $(n=45)$. Diet compliance of intervention was rated by researchers based on fruit and vegetable intake from the participant's dietary food $\log$, receipt matching, food pictures, weekly 1 hour RDN consult.

Results: Diet compliant individuals, on average, spent $\$ 95.73$ per week compared to non-compliant individuals spending $\$ 66.24$ per week. A two sample t-test with unequal variances between compliant and non-compliant participants found compliant participants spent a statistically higher amount on food $(\mathrm{p}=0.0123)$. A regression analysis controlling for age, sex, BMI, and Appalachian or non-Appalachian, also found statistical significance between compliant and non-compliant individuals $(<0.0001)$.

Conclusion: Young adults compliant with the USDA My Plate guidelines, focusing on fruit and vegetable intake, increased food cost spending by $\sim \$ 29.00$ per week. These findings can contribute to research incentive design, program planning cost, and counseling of this population.

Funding: USDA

P22 Description of Content, Sales, and Consumer Demographics of Vending Machines on a College Campus

Morgan Sowers, MS, LDN, RD, mfaulk@vols.utk.edu, The University of Tennessee, Knoxville, 1215 West Cumberland Avenue, 229 Jessie Harris Building, Knoxville, TN 37996; Sarah Colby, PhD, RD, The University of Tennessee, Knoxville; Elizabeth Anderson Steeves, PhD, RD; Katie Kavanagh, PhD, LDN, RD;
Wenjun Zhou, PhD; Melissa Olfert, DPH, MS, LDN, RD, West Virginia University; Rebecca Hagedorn, BS

Objective: Gather formative research on current contents, sales, and consumer characteristics of vending machines on a college campus.

Study Design and Setting: This study gathered content data from a purposive sample of 12 vending machines on campus (classrooms $\mathrm{n}=5$; residential $\mathrm{n}=4$; office $\mathrm{n}=3$ ) during a two-week period. Cross-sectional data were collected for sales and consumer characteristics at eight of the vending machines over a specific 4 -hour period on one weekday.

Outcome Measures and Analysis: The Nutritional Environmental Measures Survey for Vending (NEMS-V) was used to measure proportion of 'healthy' items. Sales were recorded using purchase counts by half-hour. Intercept surveys gathered student customer demographics and vending usage. Data were analyzed to provide descriptive statistics.

Results: Content assessment indicated $6.3 \%$ of all vending items were 'healthy'. A total of 99 purchases were made from all machines, with the most popular location being residential ( $\mathrm{M}=15$ purchases per machine) and times being between 1:00 and 2:00 p.m. (40\% of total purchases). Of the 111 students who completed the intercept surveys, a majority were female $(58.4 \%)$, white $(86.5 \%)$ and averaged $21.2( \pm 3.1)$ years of age. Almost half $(45 \%)$ of students purchased items from vending machines on campus one time per month or less. The most common reasons for purchase and choice were hunger (61.3\%; $42.3 \%)$ and cravings $(34.2 \%$; 59.5\%). Most students reported they would change usual vending purchases if there were healthier options $(60.4 \%)$ or changes in price (60.4\%).

Conclusions and Implications: The formative research from this study may be useful in developing interventions to improve the healthy vending options on a college campus.

Funding: USDA

\section{P23 East Asian International Students' Perceptions, Attitudes, and Behaviors in Relation to US Food and the Food Environment}

Jong Min Lee, MS, jml2231@tc.columbia.edu, Columbia University, 525 West 120th Street, New York, NY 10027; Isobel Contento, PhD, Columbia University; Heewon Lee Gray, $P h D, R D$, University of South Florida

Objective: To understand East Asian international students' changes in food consumption and the reasons why, and how they relate to their awareness and concerns about U.S. food system issues.

Study Design, Settings, Participants: A cross-sectional design using an online survey administered to East Asian international students $(\mathrm{n}=511$; female $67.1 \%$; mean age 24.8 
P23 (continued)

years;) at two public and two private universities in the New York City area.

Outcome Measures and Analysis: Frequencies, t-tests, and correlational analyses were performed to understand the changes in food consumption and reasons for the change. Multiple regression analysis was performed to predict attitudes toward the U.S. food system.

Results: Students eat more processed foods since coming to the U.S. The longer they stay $(\mathrm{t}=-2.74, \mathrm{p}<.01)$, the more acculturated they become $(\mathrm{r}=.173, \mathrm{p}<.001)$, and the more processed foods they eat. Reasons are convenience, wide availability, and good taste. They eat less whole foods since coming to the U.S. Reasons are time constraints, inconvenience, and expensive price. They make their choices based on nutrition, convenience, and price, but have little concern about ethics and the environment. When attitudes are favorable toward convenience, they choose more processed foods $(\mathrm{F}=3.96, \mathrm{p}<.05)$. When attitudes are favorable toward environmental concerns $(\mathrm{F}=7.03$, $\mathrm{p}<.01)$ and food safety issues $(\mathrm{F}=6.22, \mathrm{p}<.05)$, they choose more whole foods.

Conclusions and Implications: Overall, students choose foods mostly based on nutrition, health, and price and least due to environmental concerns. Therefore, raising students' awareness of food system issues when providing nutrition education is needed.

Funding: None

\section{P24 Knowledge, Perception, and Risk Reducing Behaviors Among Female College Students with Family History of Osteoporosis}

Krishna Patel, MS, RD, kpatel14@kent.edu, Kent State University, 6817 Thornwood Street, Canton, $\mathrm{OH} 44718$; Eun-Jeong $\mathrm{Ha}$, PhD, Kent State University

Objective: Family history of osteoporosis (FHO) has been recognized as one of the most important risk factors for osteoporosis development. The objective of this study was to compare modifiable risk factors, knowledge and perception about osteoporosis and risk reducing behaviors between female college students with FHO and without FHO.

Study Design, Setting, Participants: A convenience sample of 579 female college students attending a Midwestern state University were recruited. Participants completed an online survey with 67 potential questions.

Outcomes Measured and Analysis: Knowledge, perception, risk perception of osteoporosis, and perception in risk reducing behaviors were analyzed through independent t-tests. Chi-square test was performed to analyze differences in modifiable risks of osteoporosis including calcium intake, sun exposure, smoking, physical activity, and beverage consumption in two groups.

Results: Overall, $16.4 \%$ of respondents reported a FHO. Participants with FHO had significantly better knowledge, higher perception and risk perception of osteopo- rosis. They also perceived they were actively practicing osteoporosis risk reducing behaviors $(\mathrm{p} \leq 0.05)$. However, no significant difference was observed in preventative behaviors against osteoporosis including calcium intake, physical activity, caffeinated beverage consumption, sun exposure and smoking between the two groups.

Conclusions and Implications: Students with FHO had more knowledge about osteoporosis, and had higher perception and risk perception of osteoporosis, however were not engaging in adequate preventive behaviors. This study emphasizes the importance of intervention to reduce the disparity between actual and perceived engagement in preventive behaviors against osteoporosis in this population. Electronic reminders such as daily intake/activity trackers can be an effective tool to provide users with a consistent way of monitoring their intake and activities.

Funding: None

\section{P25 A Mixed-Methods Approach to Evaluate the Effectiveness of Rural Community Health Coalitions: Comparing Coalition Capacity and Social Network Analysis}

Jennifer Mansfield, BS, jmansfi@purdue.edu,

Purdue University, 700 West State Street,

West Lafayette, IN 47907; Lindley McDavid, PhD, Purdue

University; Donna Vandergraff, MS, RD; Krystal Lynch, PhD;

Dennis Savaiano, $P h D$

Objective: To determine how multiple indicators of coalition capacity (robustness, strength, sustainability, and growth) may predict effectiveness of community health coalitions in rural settings.

Study Design, Setting, Participants, Intervention: Community coalitions in two rural Midwestern counties focusing on building capacity to reduce obesity participated in this study. Local community facilitators were hired to assist coalitions in forming partnerships, creating mission statements and goals, and identifying/ addressing community needs. We are taking a novel mixed-methods approach to assess associations across indicators of coalition capacity within and between counties to determine which variables are most salient to coalition effectiveness. Participants are completing interviews and surveys over a two-year period that measure the study variables.

Outcome Measures and Analysis: Indicators of coalition capacity are being assessed using social network analysis and factor analysis to determine how assessment approaches converge. We are comparing network robustness, density, and centrality to coalition growth, health, and sustainability.

Results: We expect to demonstrate the unique and shared power of coalition capacity indicators and determine which indicators may serve as instrumental predictors of coalition effectiveness. 